\title{
Numerical Investigation of Infiltration Process with Non-uniform Flow in Soils
}

Saxena $\mathbf{P}^{*}$ and Agarwal $M$

Department of Mathematics and Astronomy, Lucknow University, Lucknow, Uttar Pradesh, India

\begin{abstract}
The investigation has been carried out to view the effect of rainfall in soils. The non-uniformly motion has been considered. The raindrop affects the soil dynamics and generates fracture. The Pressure head analysis, water content distribution, raindrop affect with various time domains has been done with Matlab. A proper case study has been done by taking sandy loam. Total head, effect on concentration, velocity profile (fluid motion in soil) can be viewed. The run off rate has also been calculated for different rainfall. The estimated analysis of rainfall on infiltration process has been shown graphically as well as in table.
\end{abstract}

Keywords: Numerical investigation; Infiltration process; Soil compaction; Velocity profile

\section{Introduction}

Soil dynamics is an important phenomenon as life of creature depends on plants and their development. Our living mechanism depends on vegetable and fruit cultivation. There are various factors which affect soil dynamics e.g. environment, water inclusion, nature of earth, weather and the most influential factor is rainfall. As heavy rainfall affect soil critically this can also damage the plants. Therefore rainfall intensity is an important factor. Other than that there are various things which affect the structure of soil e.g. tractor traffic, tillage and cattle trampling.

Gui et al. [1] has investigated soil compaction caused by wheel traffic. Pagli et al. [2] has shown that the soil compaction effect with a rubber tracked tractor was limited to surface layer only. Peng [3] studied that the soil structure can also change continuously water forces. A dual permeability model was introduced by Setadler modelling macro porous soils with a two phase. For fractured rocks, Unger et al. [4] produced dual permeability model for two phase flow.

Schulz et al. [5] had provided a different aspect that soil air can transmit pressure reactions. Various scientists have worked on soil dynamics by using some suitable software. Bastian et al. [6] has implemented TPDPM into the open source simulator DUMUX which is based on the numerical toolbox DUNE. Dumux is very useful software as it applies to different type of meshes in different dimensions for the implemented models.

Soil is a mixture of several contents, but can also be defined as the ensemble of voids or spaces existing in a given volume of soil. Mosaddeghi et al. [7] revealed that air permeability is a useful index of soil physical quality. Alaoui et al. [8] revealed that infiltration process can be investigated by simulating moisture variation using kinetic wave approach. There are various models which predict rainfall threshold triggering landslides. Guzzetti et al. [9], Brunetti et al. [10] and Sheng et al. [11] have developed models which do not account for many physical phenomenon affecting soils and do not consider climate effect, hydrological process etc. Pagano et al. [12] introduced the models which help in evaluation of landslide phenomenon. Many computational codes such as Hydrus [13] or Macro [14] are available to simulate water flow through soil. But these models do not analyze rainfall - induced landslides. Galeandro et al. [15] investigated a dual permeability model in which fractures behave as open channels. In the present work, we are focussing on infiltration process with nonuniform flow in soils.

A suitable program is developed for studying the rainfall effect on soil dynamics. The programme has been run on different time to study effect on soil deformation. A particular case has been discussed using sandy loam. Various properties e.g. Pressure head, concentration profiles, Moisture content, total head and saturation etc., has been shown in plots using simulation.

\section{Model Configuration}

The problem is formulated for investigating the effect of rainfall on soil deformation. Our model is prepared on the dual permeability concept. Soil domain has been discreatize as the combination of fractures and soil matrix. Fractures represent the macro porous domain and soil matrix represents the micro porous domain. Rainfall water flows directly into fracture while only lateral flow which is considered non-uniform is assumed in soil between fractures.

Water flow through the matrix using mixed form of Richards's equation

$$
\frac{\partial \theta}{\partial t}=\frac{\partial}{\partial x}\left(K(\psi) \frac{\partial \psi}{\partial x}\right)
$$

The initial water content is assumed to be variant for entire soil Matrix

$$
q_{x}=-K(\psi) \frac{\partial \psi}{\partial x}=\mathrm{a} \text { (vary with different cases) }
$$

The another boundary condition is

$$
\theta_{i}^{k+1}=\theta_{i}^{k}+\left(\frac{A_{i}^{k}+A_{i}^{k+1}}{A_{\text {TOTAL }}}\right)
$$

*Corresponding author: Saxena P, Department of Mathematics and Astronomy, Lucknow University, Lucknow, Uttar Pradesh, India, Tel: 09793371296; E-mail pulsxn@gmail.com

Received December 03, 2015; Accepted December 18, 2015; Published December 23, 2015

Citation: Saxena P, Agarwal M (2015) Numerical Investigation of Infiltration Process with Non-uniform Flow in Soils. J Appl Computat Math 4: 275. doi:10.4172/2168 9679.1000275

Copyright: $\odot 2015$ Saxena $\mathrm{P}$, et al. This is an open-access article distributed under the terms of the Creative Commons Attribution License, which permits unrestricted use, distribution, and reproduction in any medium, provided the original author and source are credited. 
Citation: Saxena P, Agarwal M (2015) Numerical Investigation of Infiltration Process with Non-uniform Flow in Soils. J Appl Computat Math 4: 275. doi:10.4172/2168-9679.1000275

Due to non-uniformity of fluid the hydraulic conductivity is expressed as exponential function (Figure 1).

$$
K(\psi)=K_{0} e^{f x}
$$

Using Matlab program for Richard's equation with the given boundary conditions various graphs have been plotted to study the soil dynamics with time. For Matlab the following values are opted:

$\begin{array}{ll}\mathrm{L}=400 ; & \text { \% length }[\mathrm{L}] \\ \mathrm{s} 1=0.5 ; & \text { \% infiltration velocity }[\mathrm{L} / \mathrm{T}] \\ \mathrm{s} 2=0 ; & \text { \% bottom suction head }[\mathrm{L}] \\ \mathrm{T}=500 ; & \text { \% maximum time }[\mathrm{T}] \\ \mathrm{qr}=0.218 ; & \text { \% residual water content } \\ \mathrm{f}=0.52 ; & \text { \% porosity } \\ \mathrm{a}=0.0115 ; & \text { \% van Genuchten parameter }[1 / \mathrm{L}] \\ \mathrm{n}=2.03 ; & \text { \% van Genuchten parameter } \\ \mathrm{ks}=0.02^{*} \exp (0.2 * 6.0) ; & \text { \% saturated conductivity }[\mathrm{L} / \mathrm{T}]\end{array}$

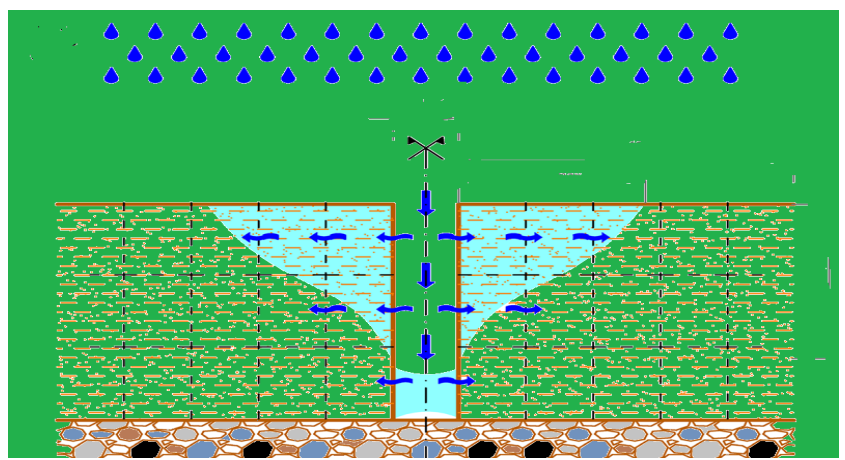

Figure 1: Schematic diagram of the problem.
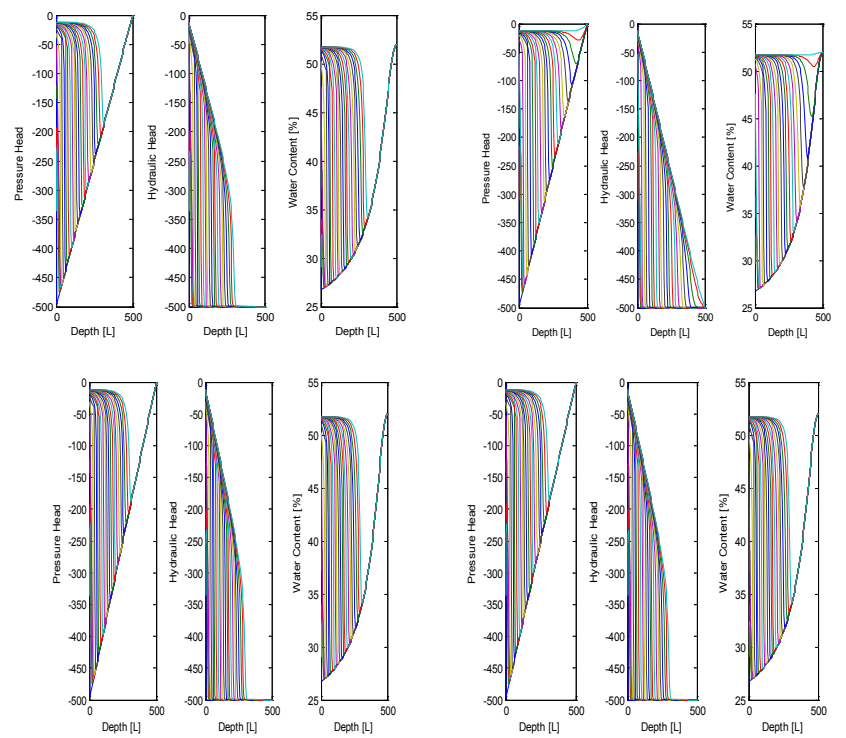

Figure 2: The pressure head distribution with different time (i) $\mathrm{T}=500$ (ii) $\mathrm{T}=$ 1000 (iii) $\mathrm{T}=1500$ (iv) $\mathrm{T}=2000$.
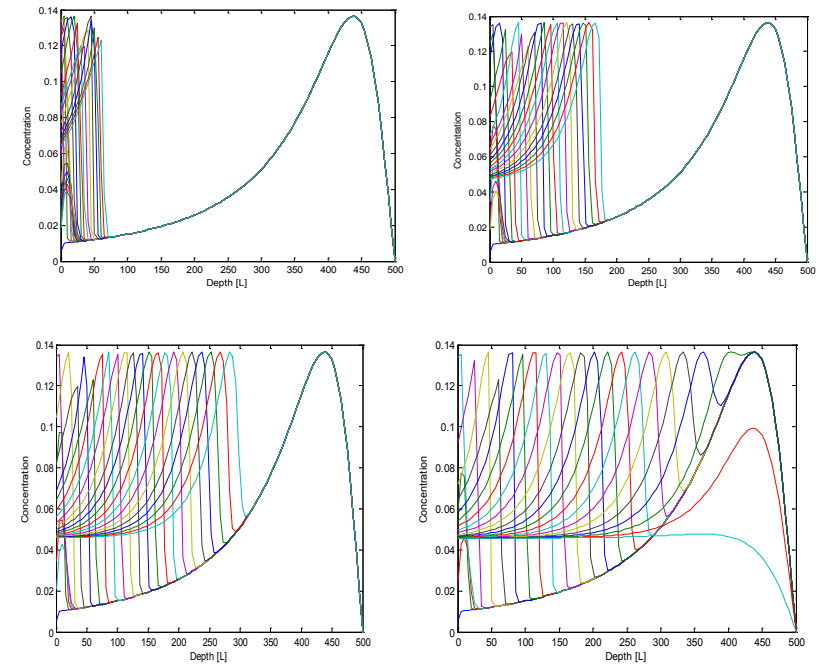

Figure 3: Concentration profiles with increasing time (i) $\mathrm{T}=500$ (ii) $\mathrm{T}=1000$ (iii) $\mathrm{T}=1500$ (iv) $\mathrm{T}=2000$.
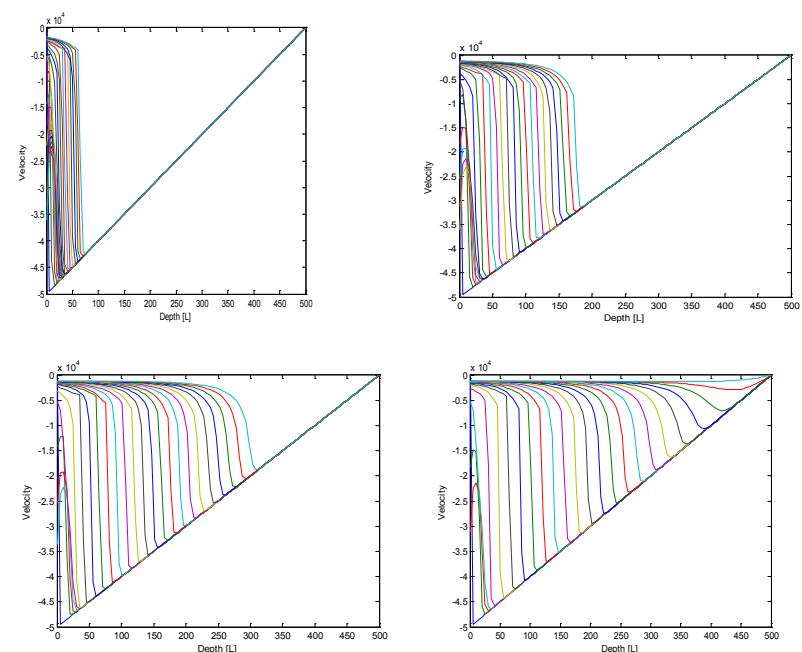

Figure 4: Velocity configuration with increasing time (i) $\mathrm{T}=500$ (ii) $\mathrm{T}=1000$ (iii) $\mathrm{T}=1500$ (iv) $\mathrm{T}=2000$.

With these parameters the Matlab programme has been run for graphical distribution of pressure head, Saturation, concentration, hydraulic head and water content.

\section{Results and Discussions}

The graph has been plotted for pressure head, Hydraulic head and water content using Matlab using the above set of parameters. The variation has been studied with time in Figure 2.

It is observed that with the increase of time pressure head increases slightly. Hydraulic head seems smooth and water content increases sharply after rainfall into the soil. Concentration of constituents after rainfall with time has been shown in Figure 3. Modulation with time with respect to distance has been investigated.

The velocity profile of rainwater into the soil has been shown in Figure 4. It increases sharply with distance. 
Citation: Saxena P, Agarwal M (2015) Numerical Investigation of Infiltration Process with Non-uniform Flow in Soils. J Appl Computat Math 4: 275. doi:10.4172/2168-9679.1000275

Saturation profile has been shown in Figure 5, which shows that soil domain seems more and more saturated with time and runoff will occur after a certain limit, which has been studied afterwards.

\section{A case study}

A rectangular mesh is considered. The length unit is meter. Time unit is hour and mass unit is gram. The model is used to simulate transport under flow profile specify hydraulic condition as equilibrium profile. Intercell hydraulic conductivity is computed using arithmetic mean module. Hydraulic characteristic functions have been represented using Van Genuchten model. The difference scheme is implemented centred in space for proper consideration of nonuniform motion. Under solver options the relaxation parameter is 0.7 . Minimum iteration per time step is 500. Closure criterion head is 0.001 . The output has been observed in terms of different output variables.

The case is considered for sandy loam. The proper parameter has been used for running simulation. The porosity is 0.496 , with specific storage 0.0292. Initial concentration is assumed to be constant for whole domain. The suitable recharge period has been chosen for proper running the simulation during rainfall. Initial time step is 0.01 , time step multiplier is 1.2 , time step reduction factor is 1.0 and max. Height of ponding is 100.0 (Figures 6.1-12.4 and Tables 1-6).
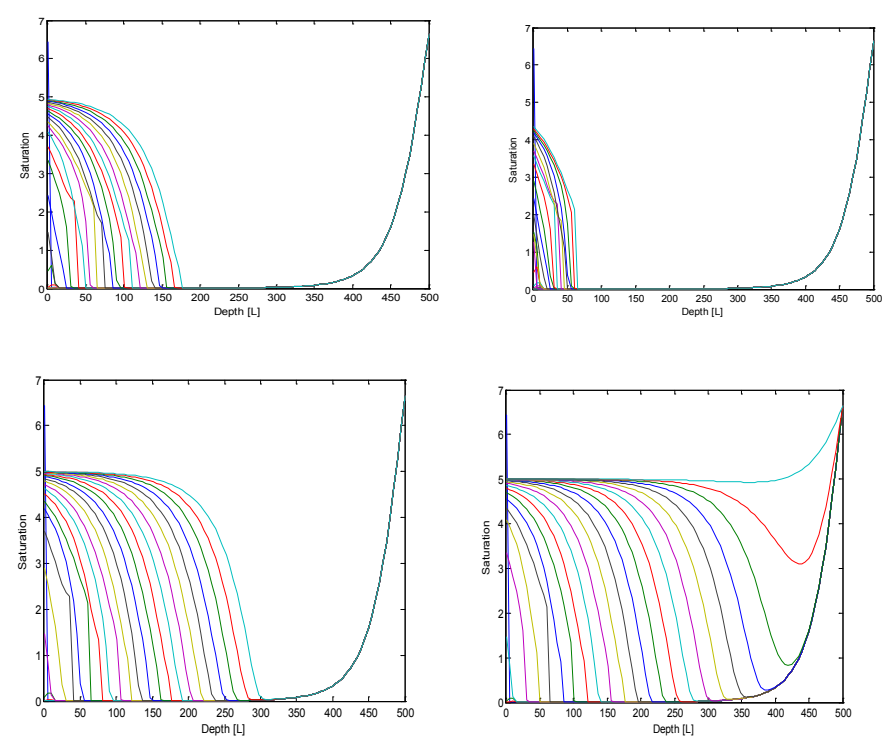

Figure 5: Saturation against depth with time (i) $\mathrm{T}=500$ (ii) $\mathrm{T}=1000$ (iii) $\mathrm{T}=1500$ (iv) $\mathrm{T}=2000$.

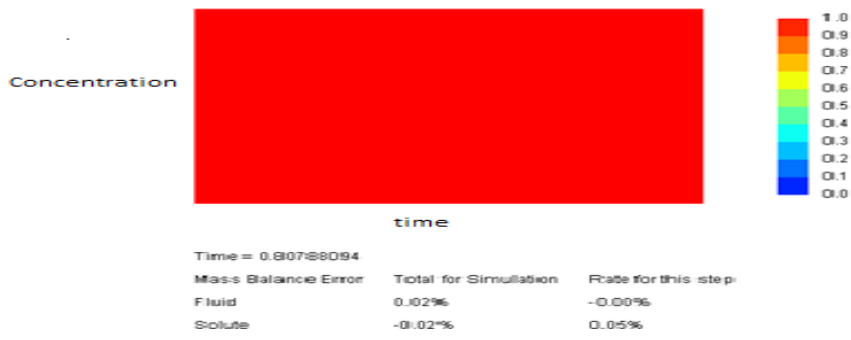

Figure 6.1: Concentration against time $(\mathrm{t}=0.80)$.

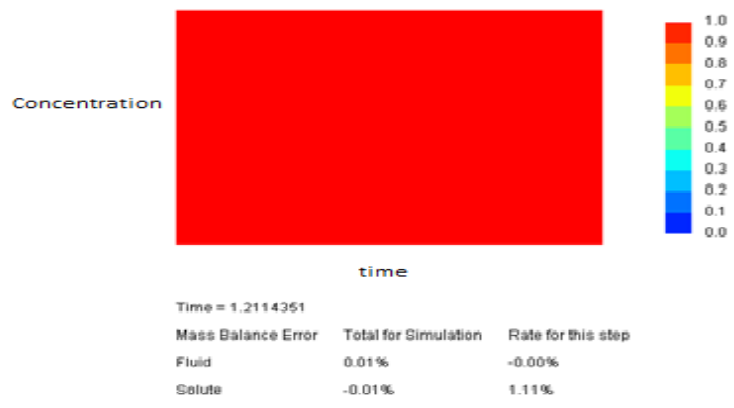

Figure 6.2: Concentration against time $(\mathrm{t}=1.21)$. 


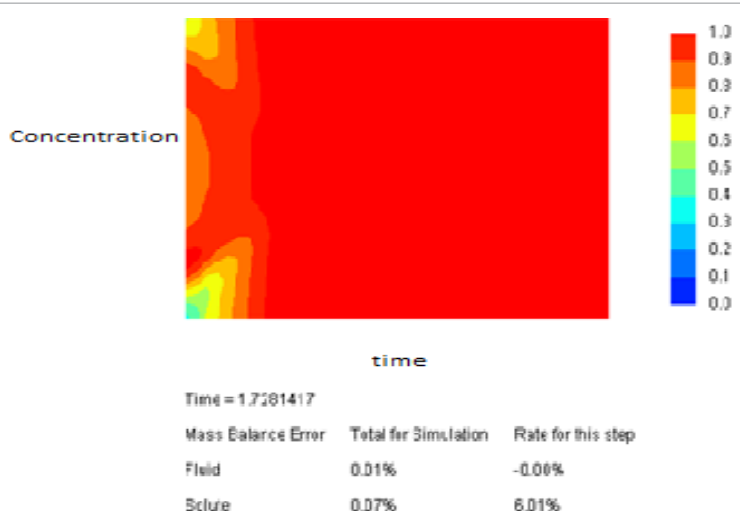

Figure 6.3: Concentration against time $(\mathrm{t}=1.71)$.

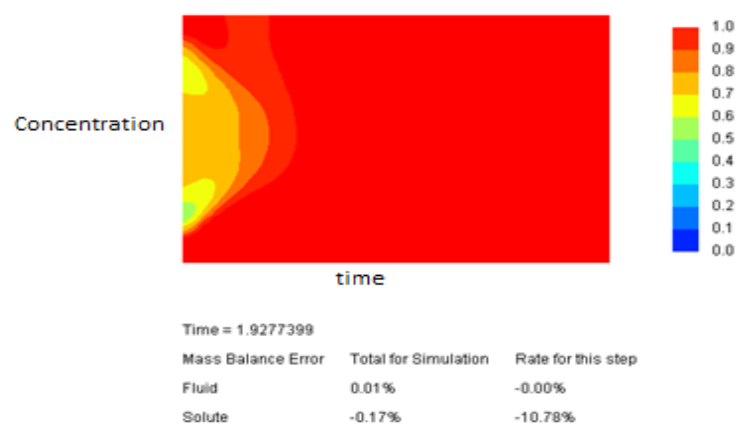

Figure 6.4: Concentration against time $(\mathrm{t}=1.92)$.

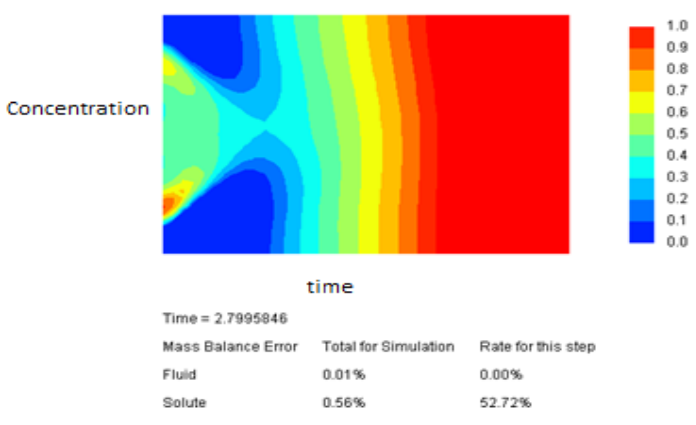

Figure 6.5: Concentration against time $(\mathrm{t}=2.79)$.

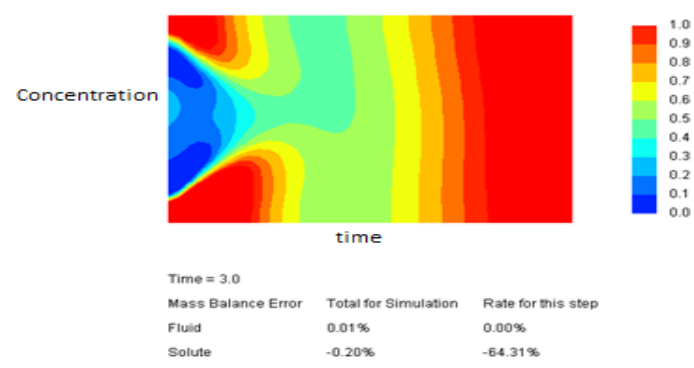

Figure 6.6: Concentration against time $(t=3.0)$. 


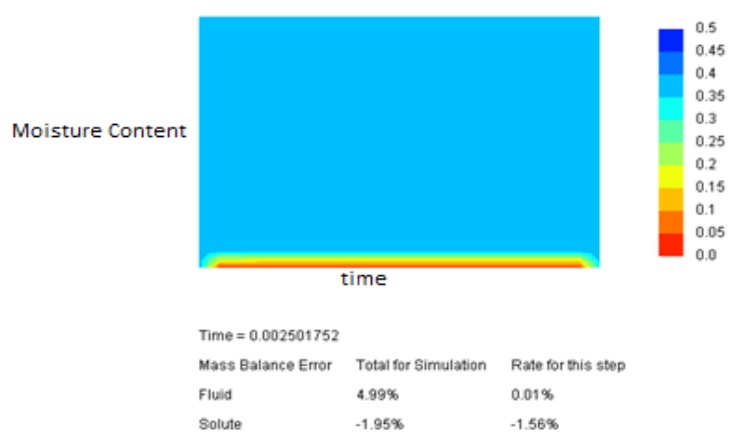

Figure 7.1: Moisture content against time $(\mathrm{t}=.002)$.

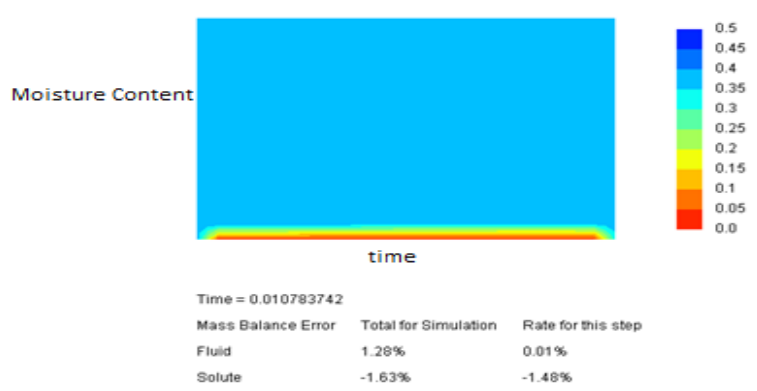

Figure7.2: Moisture content against time $(\mathrm{t}=.01)$

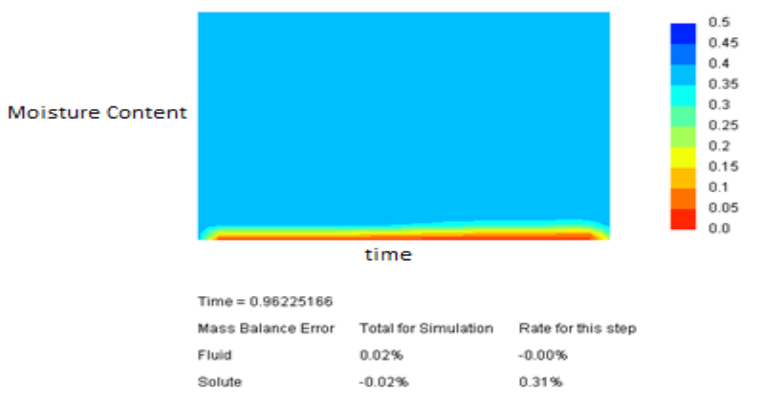

Figure 7.3: Moisture content against time $(\mathrm{t}=0.96)$.

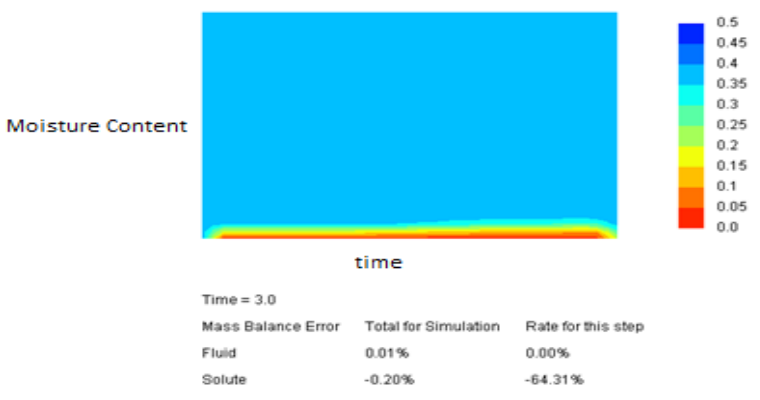

Figure 7.4: Moisture content against time $(t=3.0)$. 


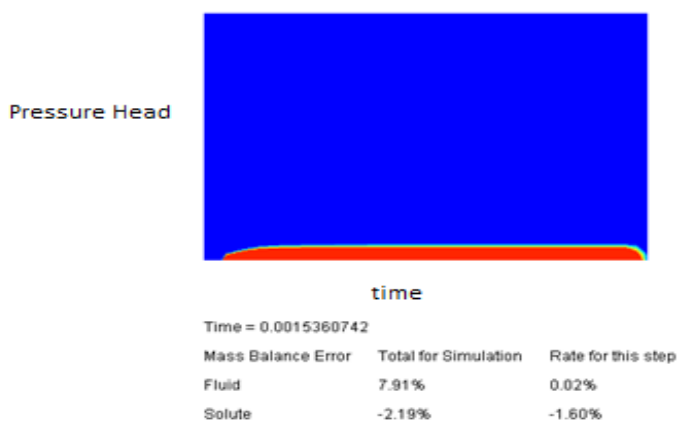

Figure 8.1: Pressure head against time $(t=0.0015)$.

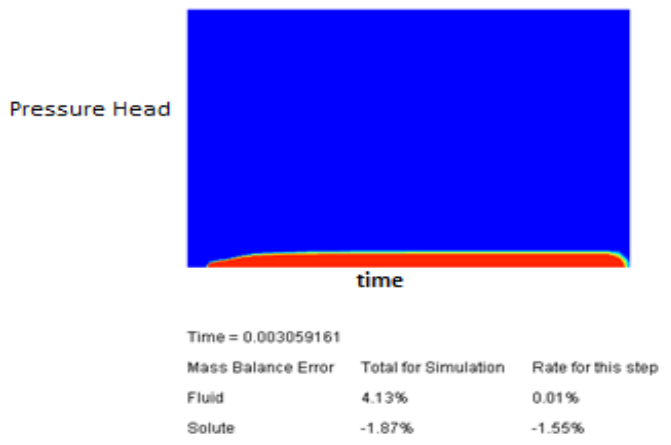

Figure 8.2: Pressure head against time $(\mathrm{t}=0.003)$

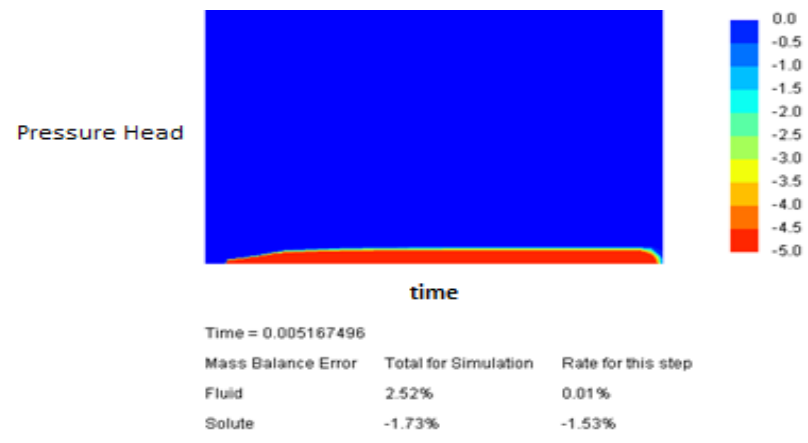

Figure 8.3: Pressure head against time $(t=0.005)$

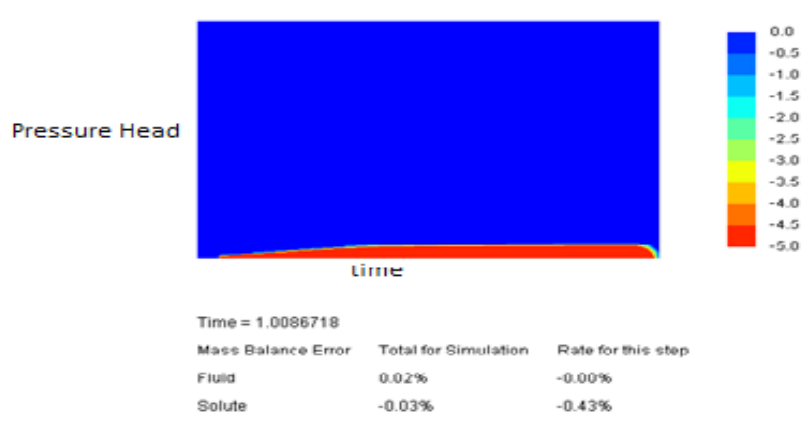

Figure 8.4: Pressure head against time $(t=1.00)$. 


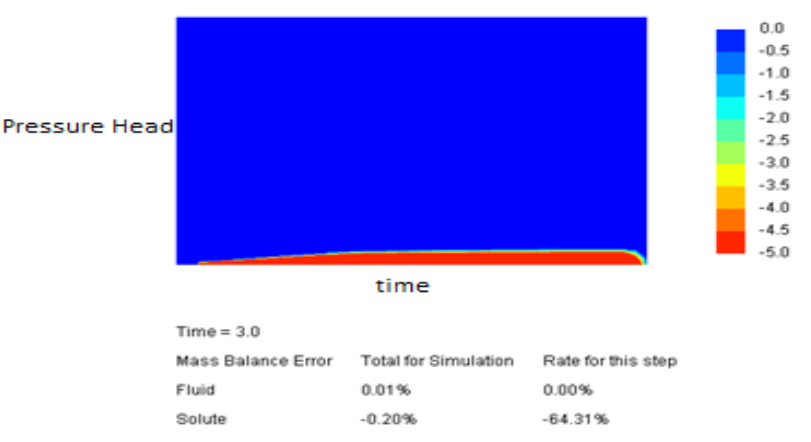

Figure 8.5: Pressure head against time $(t=3.0)$.

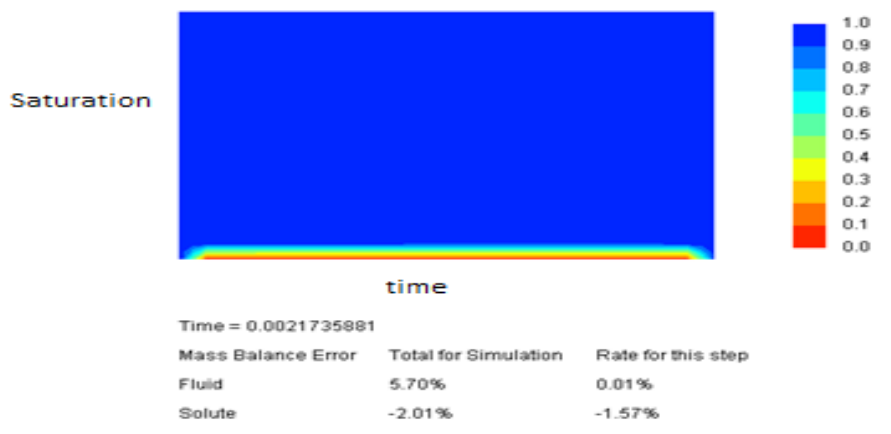

Figure 9.1: Saturation against time $(\mathrm{t}=.0021)$.

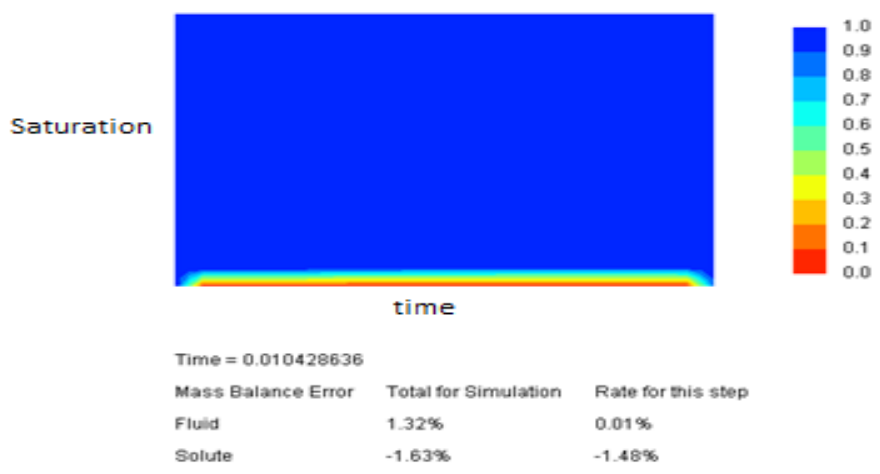

Figure 9.2: Saturation against time $(\mathrm{t}=0.0104)$.

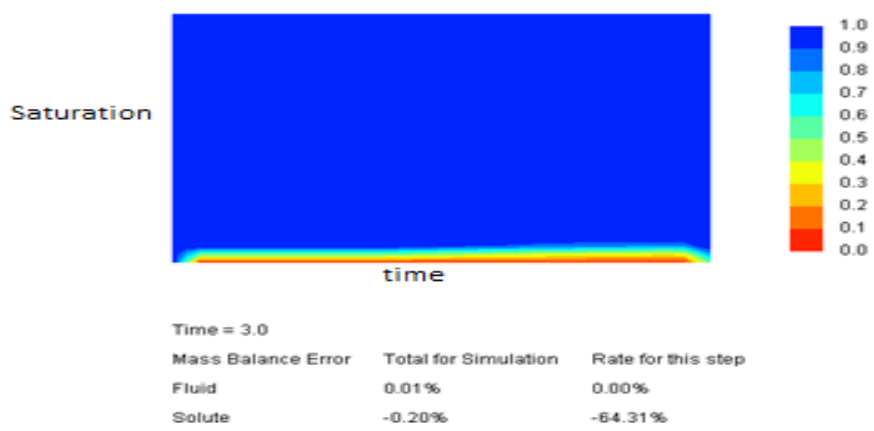

Figure 9.3: Saturation against time $(t=3.0)$. 


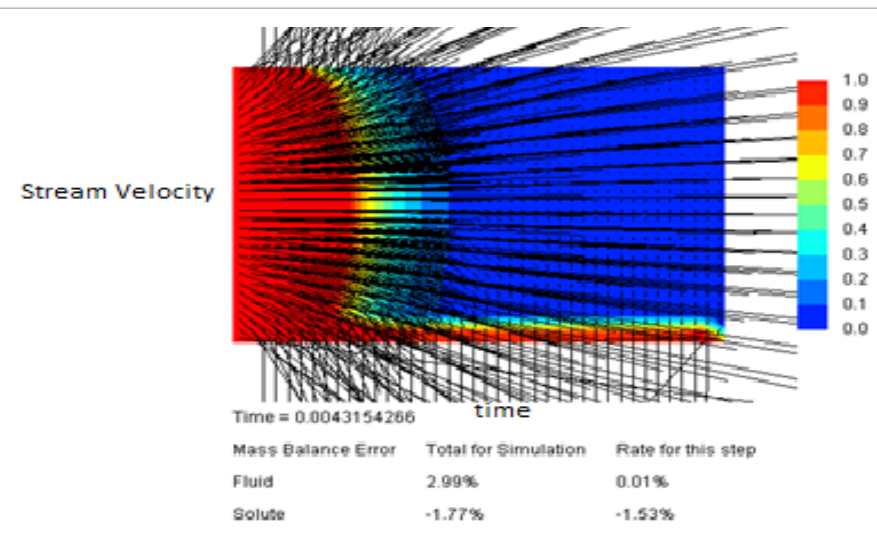

Figure 10.1: Stream velocity against time $(t=0.004)$

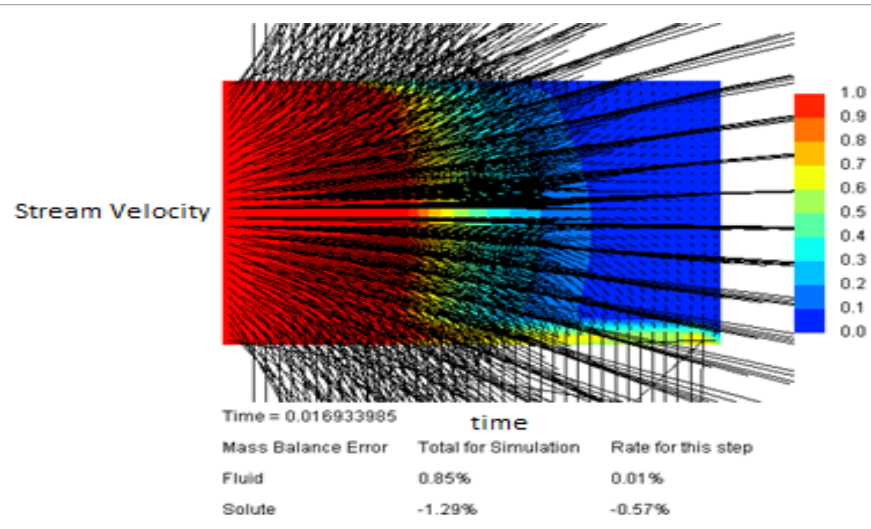

Figure 10.2: Stream velocity against time $(\mathrm{t}=0.0169)$

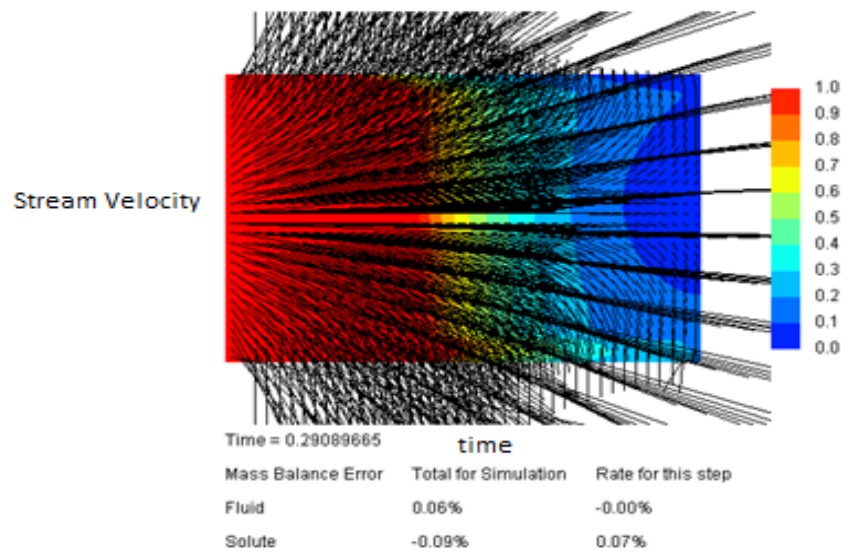

Figure 10.3: Stream velocity against time $(t=0.29)$ 


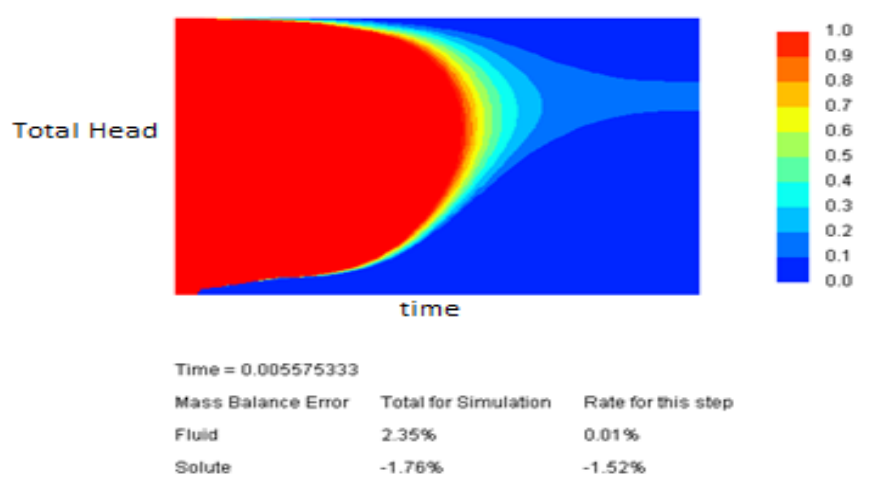

Figure 10.4: Stream velocity against time $(t=3.0)$

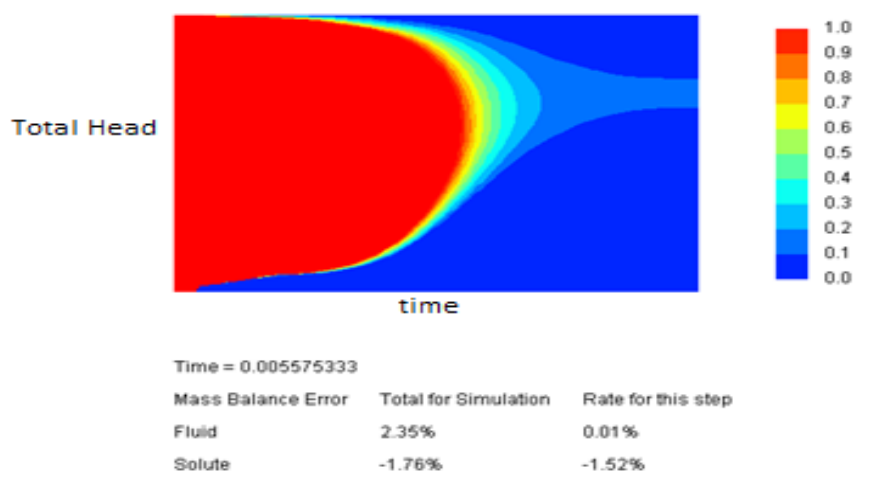

Figure 11.1: Total head against time $(\mathrm{t}=.0055)$.

Total Head

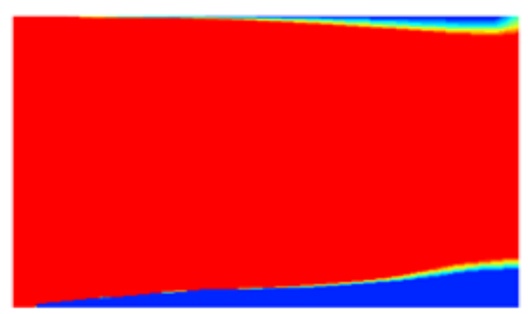

time

Time $=0.24751057$

Mass Balance Error Total for Simulation Rate for this step

$\begin{array}{lll}\text { Fluid } & 0.07 \% & 0.00 \% \\ \text { Solute } & -0.11 \% & 0.07 \%\end{array}$

Figure 11.2: Total head against time $(\mathrm{t}=0.247)$. 


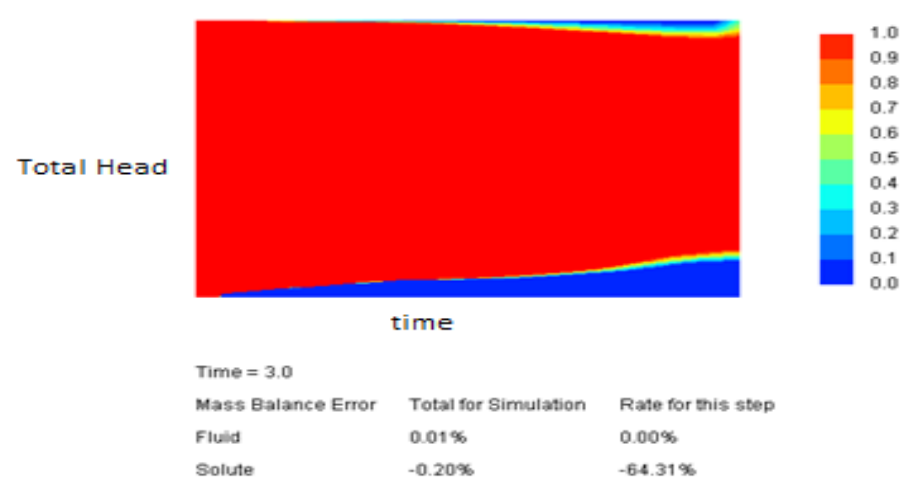

Figure 11.3: Total head against time $(\mathrm{t}=3.0)$.

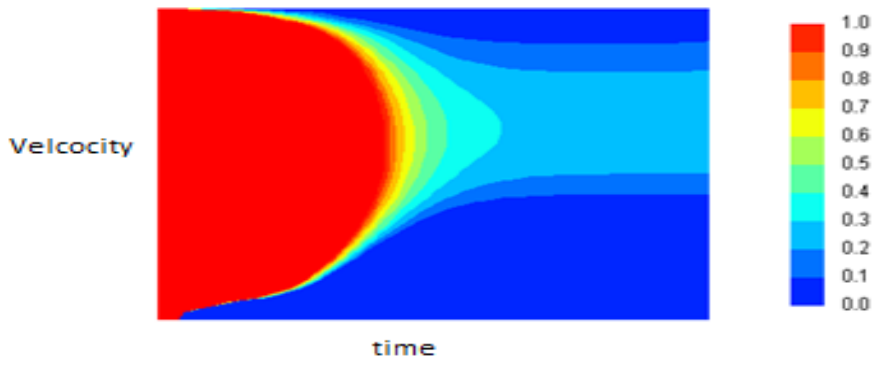

Time $=0.0025306214$

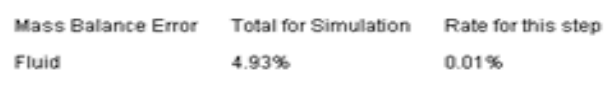

$\begin{array}{lll}\text { Solute } & -1.94 \% & -1.56 \%\end{array}$

Figure 12.1: Velocity against time $(\mathrm{t}=0.0025)$.

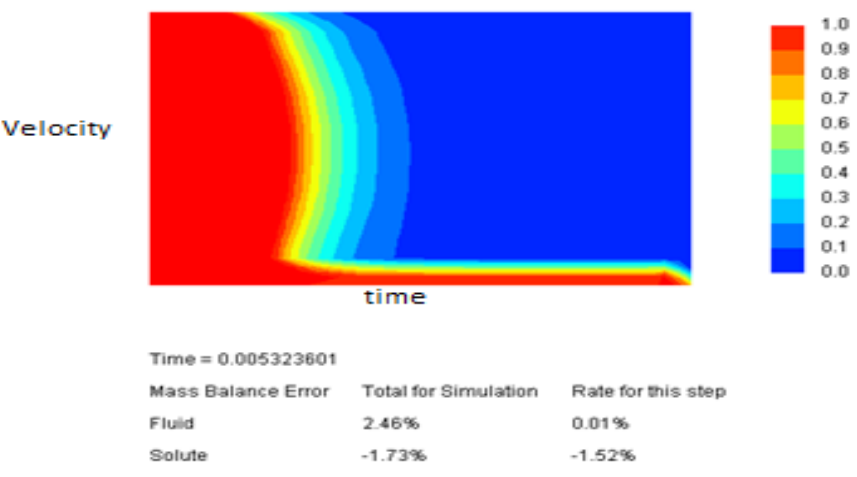

Figure 12.2: Velocity against time $(t=0.005)$ 
Citation: Saxena P, Agarwal M (2015) Numerical Investigation of Infiltration Process with Non-uniform Flow in Soils. J Appl Computat Math 4: 275. doi:10.4172/2168-9679.1000275

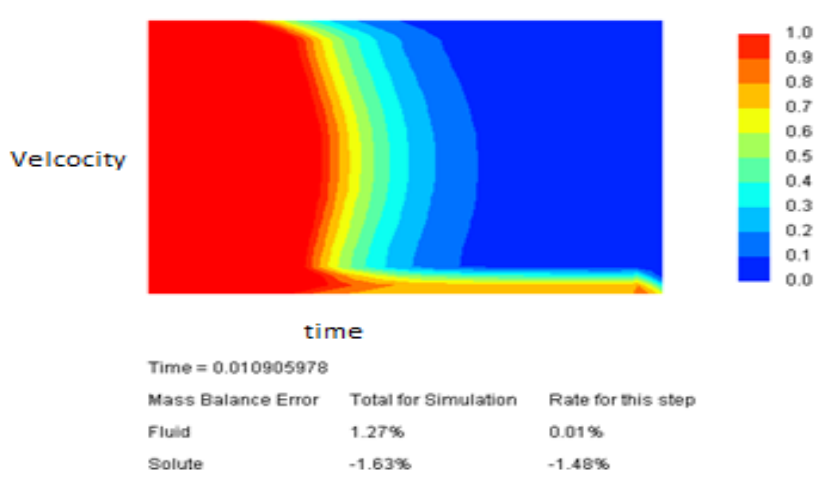

Figure 12.3: Velocity against time $(t=0.010)$.

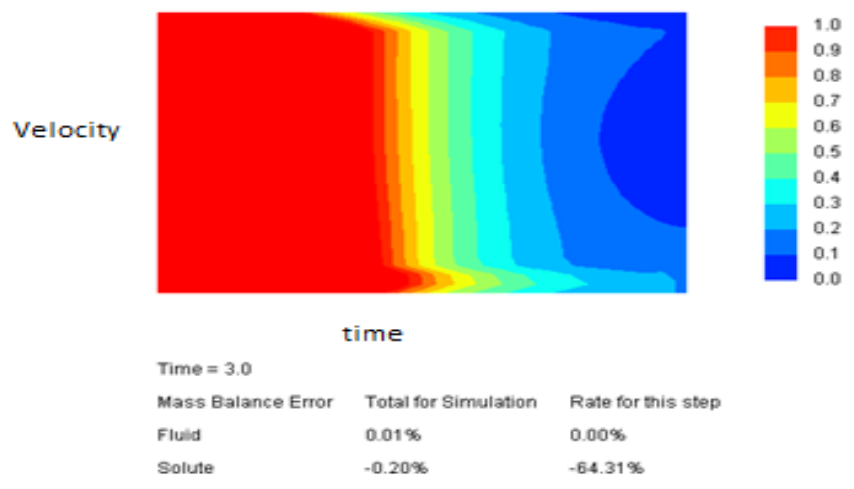

Figure 12.4: Velocity against time $(\mathrm{t}=3.0)$.

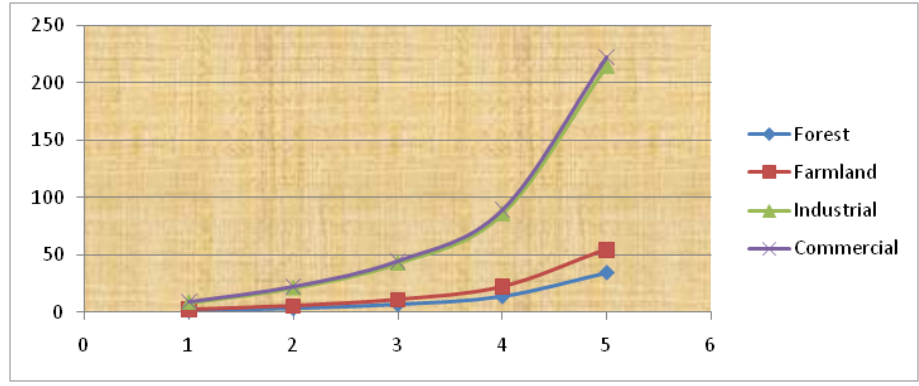

Figure 13: Graph of peak runoff rate against rainfall intensity for different lands.

\begin{tabular}{|l|c|c|c|c|c|}
\hline Time & $\mathbf{0 . 8}$ & $\mathbf{1 . 2}$ & $\mathbf{1 . 7}$ & $\mathbf{1 . 9}$ & $\mathbf{3 . 0}$ \\
\hline Fluid/solute & $.02 /-.02$ & $.05 /-.01$ & $.01 /-.17$ & $.01 /-0.17$ & $.01 /-.56$ \\
\hline
\end{tabular}

Table 1: Concentration.

\begin{tabular}{|l|c|c|c|c|c|}
\hline Time & $\mathbf{0 . 0 0 2}$ & $\mathbf{0 . 0 1}$ & $\mathbf{0 . 9 6}$ & $\mathbf{3 . 0}$ & $\mathbf{3 . 0}$ \\
\hline Fluid/solute & $4.99 /-1.95$ & $1.20 /-1.67$ & $0.02 /-.02$ & $.01 /-.20$ & $.01 /-.56$ \\
\hline
\end{tabular}

Table 2: Moisture content. 
Citation: Saxena P, Agarwal M (2015) Numerical Investigation of Infiltration Process with Non-uniform Flow in Soils. J Appl Computat Math 4: 275. doi:10.4172/2168-9679.1000275

Page 12 of 13

\begin{tabular}{|l|c|c|c|}
\hline Time & $\mathbf{0 . 0 0 2}$ & $\mathbf{0 . 0 1}$ & $\mathbf{0 . 0 1 9}$ \\
\hline Fluid/solute & $5.7 /-2.01$ & $1.32 /-1.63$ & $.01 /-.20$ \\
\hline
\end{tabular}

Table 3: Saturation

\begin{tabular}{|l|c|c|c|c|c|}
\hline Time & $\mathbf{0 . 0 0 0 1}$ & $\mathbf{0 . 0 0 4 3}$ & $\mathbf{0 . 0 1}$ & $\mathbf{0 . 2 9}$ & $\mathbf{3 . 0}$ \\
\hline Fluid/solute & $1.65 /-1.68$ & $2.99 /-1.29$ & $.05 /-1.29$ & $.06 /-.09$ & $.01 /-.30$ \\
\hline
\end{tabular}

Table 4: Stream velocity configuration.

\begin{tabular}{|l|c|c|c|}
\hline Time & $\mathbf{. 0 0 5 5}$ & $\mathbf{. 0 1 5}$ & $\mathbf{. 2 4 9}$ \\
\hline Fluid/solute & $2.35 /-1.76$ & $0.99 /-1.33$ & $.07 /-0.11$ \\
\hline
\end{tabular}

Table 5: Total head.

\begin{tabular}{|l|c|c|c|c|c|c|}
\hline Time & $\mathbf{. 0 0 2 5}$ & $\mathbf{. 0 0 2 5 5}$ & $\mathbf{. 0 0 0 5}$ &. $\mathbf{0 0 5 3}$ & $\mathbf{. 0 1}$ & $\mathbf{0 . 5}$ \\
\hline Fluid/solute & $4.93 /-1.94$ & $4.00 /-1.96$ & $2.50 /-1.73$ & $2.46 /-1.73$ & $1.27 /-1.63$ & $.03 /-.03$ \\
\hline
\end{tabular}

Table 6: Velocity configuration.

\section{Raindrop estimation}

The raindrop estimation is calculated using the suitable formula:

$$
r_{j}=\frac{k_{0} f\left(\Delta \psi+I_{j}+\Delta I_{j} / \Delta \theta\right)}{I-e^{f\left(I+\Delta I_{J}\right)} / \Delta \theta}
$$

Where $r_{j}$ is the rainfall rate at time step $j, z_{j}$ is the cumulative infiltration in time steps 1 to $j-1$ and $I_{j}$ is the infiltration volume prior to ponding in time step $\mathrm{j}$. If the solution yields $\mathrm{I}_{\mathrm{J}}>\mathrm{r}_{\mathrm{j}} \Delta \mathrm{t}$, where $\Delta \mathrm{t}$ the time step is then there is no ponding in the time step and all the rainfall infiltrates. The expression to calculate $\mathrm{I}_{\mathrm{j}+1}$ is given as:

$$
I_{j+1}=I_{j}+r_{j} \Delta t
$$

\section{Theoretical background}

The peak runoff rate can be calculated theoretically using the simple expression given below under some assumptions (Figure 13):

1. Consideration of the entire drainage area as a single unit.

2. Estimation of flow at the most downstream point only.

3. The assumption that rainfall is uniformly distributed over the drainage area.

$$
\begin{aligned}
& \mathrm{Q}_{\mathrm{P}}=0.28{ }^{*} \mathrm{C}^{*} \mathrm{I}^{*} \mathrm{~A} \\
& \mathrm{Q}_{\mathrm{P}}=\text { Peak runoff rate }\left[\mathrm{m}^{3} / \mathrm{sec}\right] \\
& \mathrm{C}=\text { Runoff Coefficient }[-] \\
& \mathrm{I}=\text { Rainfall intensity }[\mathrm{mm} / \mathrm{hr}] \\
& \mathrm{A}=\text { Drainage area }\left[\mathrm{Km}^{2}\right]
\end{aligned}
$$

\section{Conclusions}

The main objective of this study is to analyse the effect of rainfall on the soil dynamics and what is the requirement of soil constituents before replanting. In this investigation, pattern of surface runoff has been studied for various fields and compared to evaluate the degree of damage caused by soil erosion. Raindrop estimation has been done to assess the water ponding on the surface. Using suitable software a proper case study has been done to analyse the concentration analysis, moisture content and pressure drop etc., for proper assessment of soil constituents like nitrogen, phosphorous etc., before replanting.

\section{Acknowledgement}

The author Parul Saxena is thankful to the Department of Science and Technology, New Delhi for Financial support under the project SR / WOS - A / MS - 23 / 2013 and to the Dept of Mathematics and Astronomy, Lucknow University, Lucknow for providing research facilities during the work.

\section{References}

1. Gui DW, Lei JQ, Zeng FJ, Mu GJ, Zhu JT, et al. (2010) Characterizing variations in soil particle size distribution in oasis farmlands: A case study of the Cele Oasis. Mathematical and Computer Modelling 51: 1306-1311.

2. Pagliai M, Marsili A, Servadio P, Vignzzi N, Pellegrini S (2003) Changes in some physical properties of a clay soil in Central Italy following the passage of rubber tracked and wheeled tractors of medium power. Soil Till Res 73: 119-129.

3. Peng X, Horn R, Smucker A (2007) Pore shrinkage dependency of inorganic and organic soils on wetting and drying cycles. Soil Sci Soc Am J 71: 10951104.

4. Unger AJA, Faybishenko B, Bodvarsson GS, Simmons AM (2004) Simulating infiltration tests in fractured basalt at the box canyon site, idaho. Vadose Zone J 3: 75-89.

5. Schulz WH, Kean JW, Wang G (2009) Landslide movement in southwest Colorado triggered by atmospheric tides. Nat Geosci 2: 863-866.

6. Bastian P, Blatt M, Dedner A, Engwer C, Klöfkorn R, et al. (2008) A generic grid interface for parallel and adaptive scientific computing. Computing 82: 103-119.

7. Mosaddeghi MR, Koolen AJ, Hajabbasi MA, Hemmat A, Keller T (2007) Suitability of pre-compression stress as the real critical stress of unsaturated agricultural soils. Biosys Eng 98: 90-101.

8. Alaoui A, Germann P, Jarvis N, Acutis M (2003) Dual-porosity and kinematic wave approaches to assess the degree of preferential flow in an unsaturated soil. Hydrol Sci J 48: 455-472.

9. Guzzetti F, Peruccacci S, Rossi M, Stark CP (2008) The rainfall intensityduration control of shallow landslides and debris flows: an update. Landslides 5: 3-17.

10. Brunetti MT, Peruccacci S, Rossi M, Guzzetti F, Reichenbach P, et al. (2009) A prototype system to forecast rainfall-induced landslides in Italy. In: Picarelli $L$, Tommasi P, Urciuoli G, Versace P (eds.) Proceedings of 1st Italian Workshop on Landslides, Rainfall-Induced Landslides: Mechanisms, monitoring techniques and now casting models for early warning systems. Naples, Italy 1: 157-161.

11. Sheng F, Wang K, Zhang R, Liu H (2011) Modeling preferential water flow and solute transport in unsaturated soil using the active region model. Environ Earth Sci 62: 1491-1501.

12. Pagano L, Picarelli L, Rianna G, Urciuoli G (2010) A simple numerical procedure for timely prediction of precipitation induced landslides in unsaturated pyroclastic soils. Landslides 7: 273-289. 
Citation: Saxena P, Agarwal M (2015) Numerical Investigation of Infiltration Process with Non-uniform Flow in Soils. J Appl Computat Math 4: 275. doi:10.4172/2168-9679.1000275

Page 13 of 13

13. Simunek J, Kohne JM, Kodesova R, Ejna MS (2008) Simulating non equilibrium movement of water, solutes, and particles using Hydrus: A review of recent applications. Soil Water Res 3: 42-51.
14. Larsbo M, Jarvis N (2005) Simulating solute transport in a structured field soil: Uncertainty in parameter identification and predictions. J Environ Qual 34: 621-634.

15. Galeandro A, Doglioni A, Simeone V, Simunek J (2014) Analysis of infiltration processes into fractured and swelling soils as triggering factors of landslides. Environ Earth Sci 71: 2911-2923. 